\title{
Rate of breast biopsy referrals in BRCA mutation carriers: a retrospective comparative study and matched analysis
}

Adi Pomerantz ( $\sim$ adi.pomerantz@gmail.com )

Rabin Medical Center Davidoff Center https://orcid.org/0000-0003-1587-3501

Daliah Tsoref

Rabin Medical Center Davidoff Center

Ahuva Grubstein

Beilinson Hospital: Rabin Medical Center

Sonya Wadhawker

Beilinson Hospital: Rabin Medical Center

Yael Rapson

Beilinson Hospital: Rabin Medical Center

Itay Gadiel

Beilinson Hospital: Rabin Medical Center

Hadar Goldvaser

Rabin Medical Center Davidoff Center

Ariel Hammerman

Clalit Health Services

Tzipora Shochat

Beilinson Hospital: Rabin Medical Center

Eran Sharon

Beilinson Hospital: Rabin Medical Center

Rinat Yerushalmi

Rabin Medical Center Davidoff Center

\section{Research Article}

Keywords: Biopsy, BRCA, breast cancer, screening, high risk

Posted Date: July 8th, 2021

DOl: https://doi.org/10.21203/rs.3.rs-670565/v1 
License: (c) (i) This work is licensed under a Creative Commons Attribution 4.0 International License. Read Full License 


\section{Abstract \\ Purpose}

To evaluate the total biopsy and positive biopsy rates in women at high risk of breast cancer compared to the general population.

\section{Methods}

The study group consisted of $330 B R C A$ mutation carriers attending the dedicated multidisciplinary breast cancer clinic of a tertiary medical center in Israel. Clinical, genetic, and biopsy data were retrieved from the central healthcare database and the medical files. Patients who were at age 50 years or older during follow-up were matched 1:10 to women in the general population referred for routine breast cancer screening at the same age, as recommended in the international guidelines. The groups were compared for rate of biopsy studies performed and percentage of positive biopsy results. Matched analysis was performed to correct for confounders.

\section{Results}

The matched analysis revealed that the total biopsy rate per 1000 follow-up-years was 61.7 in the study group and 22.7 in the control group $(p<0.001)$. The positive biopsy rates per 1000 follow-up-years were 26.4 and 2.0 , correspondingly $(p<0.001)$, and the positive biopsy percentages were $42.9 \%$ and $8.7 \%$ correspondingly $(p<0.0001)$.

\section{Conclusions}

$B R C A$ mutation carriers who attend a dedicated clinic, have a 2.7 times higher biopsy rate per 1000 follow-up-years, a 13.2 times higher positive biopsy rate per 1000 follow-up-years, and a 4.9 times higher positive biopsy percentage compared with women in the general population.

\section{Background}

Breast cancer is the most frequent diagnosed cancer and the leading cause of cancer-related death in women. It accounts for $23 \%$ of total cancer cases and $14 \%$ of cancer mortality worldwide [1]. In addition to clinical parameters, namely female sex, older age, and exposure to estrogen, genetic factors play an important role in breast cancer risk [2]. New technologies that enable efficient genomic sequencing at relatively low cost have been implemented in the last decade. This has enriched our knowledge with respect to gene mutations and their role in disease development. In the mid-1990s, newly developed genomic sequencing techniques revealed a link between germline mutations in the tumor-suppressor genes BRCA1, located on chromosome 17 [3, 4], and BRCA2, located on chromosome 13 [5], with breast 
and ovarian cancer $[6,7]$. Women who carry the gene mutation have up to $80 \%$ lifetime chance of developing cancer, primarily of breast and ovarian origin. These mutations were found to be inherited in an autosomal dominant manner with high penetrance.

Since then, great efforts have been invested to increase public awareness of breast cancer and to identify women at high risk. Women with a family history of multiple malignancies, especially breast and ovarian carcinoma are offered genetic counseling. In some cases, the trigger for such testing is the identification of a mutation carrier within the family, which results in subsequent testing of additional family members. Once the genetic institute identifies a woman as a carrier, she is invited to meet with a genetic counselor who elaborates the significance of the results; namely, the risk of developing various malignancies, the potential preventive treatment options available, and recommended follow-up algorithms. Those found to be $B R C A$ mutation carriers are encouraged to start rigorous multidisciplinary follow-up from age 25 years, as recommended by international guidelines [8-10], often at dedicated clinics. This includes biannual breast examination, gynecological examination, vaginal ultrasound, and CA-125 blood test, in addition to annual mammography, breast ultrasound, and breast MRI (magnetic resonance imaging) [11]. Imaging findings are categorized using the BI-RADS (Breast Imaging-Reporting and Data System), with scores ranging from 0 (incomplete) to VI [12]. BI-RADS score of IVa-c, low-high level of suspicion; V-highly suggestive of malignancy) is an indication for a biopsy; VI-known malignancy.

The confirmation of being a carrier is described by many women as overwhelming and, indeed, constitutes a life-changing event. The carriers undergo many imaging tests during their lifetime. As expected they are prone to an increased rate of biopsies for suspicious lesions. Knowing their absolute risk may lead to lowering the threshold of recommending a biopsy compared to the general population.

Study Objective

The first objective of the study was to evaluate the rate and yield of biopsies performed in BRCA mutation carriers in our BRCA clinic. As a second objective, we aimed to investigate the rate and yield of biopsy in BRCA carriers who attend the clinic compared to the general population. The findings are intended to help carriers to better understand what they need to cope with and to guide health systems in allocating testing and resources.

\section{Methods}

\section{Design and Setting}

The first part was simply reporting the rate of biopsies (number of biopsies / screening episodes in years) for the entire study group including the leading test to biopsy and its result. The follow-up period was between May 2000 and September 2019. The study group consisted of consecutive BRCA1 or BRCA2 mutation carriers who underwent follow-up at the tertiary breast cancer clinic of Davidoff Center, Rabin Medical Center, in Israel. 
The clinic provides comprehensive follow-up for women with $B R C A$ mutations based on international guidelines including psychological counseling. Women in whom breast/ovarian cancer developed before they were identified as BRCA mutation carriers were excluded.

The second part of the study was a matched analysis based on the retrospective cohort.

The follow-up period was between January 2002 and June 2019 for both cases and controls.

The control group consisted of women at average risk who underwent routine breast cancer screening In Israel. The screening program for women at average risk for breast cancer starts at the age of age 50 years [8-10]. Therefore, for purposes of comparison, we matched $B R C A$ mutation carriers who are 50 years or more with 10 control women.

For comparison with the general population, 113 women with a $B R C A$ mutation who were at age 50 years or older during follow-up were found. Thirty-four women were older than 50 years on 2002 and were excluded. Seven women were not eligible for the regular screening tests through Clalit Health Services (CHS) and were excluded. Eleven women developed breast cancer before the beginning of the follow-up or before age 50 years and were excluded. The remaining 61 women were matched to 610 women from the total 276,979 women who had undergone routine breast cancer screening during the study period. Women who started follow-up before the age 50 years or underwent breast MRI on a regular basis were excluded from the control group.

Rabin Medical Center belongs to CHS, the largest of four health maintenance organizations in Israel. CHS manages a central computerized healthcare warehouse that integrates data from its hospitals, community clinics, laboratories, and pharmacies. For purposes of the study, clinical, imaging, biopsy, and operative data were retrieved from the central database and hospital medical records.

The study was approved by the local Institutional Ethics Committee.

\section{Statistical Analysis}

The rate of biopsies performed per exposure period was compared between groups using the conditional test with Mid-P adjustment. The positive biopsy ratio was calculated using chi-square test ( $w i t h \mathrm{df}=1$ ). Matching analysis was performed for the following confounders: age group (50,51-55, 56-60, 61-65 years), socioeconomic status, Charlson Comorbidity Index score $(0,1,2-3)$, sector (orthodox Jewish, non orthodox Jewish), use of hormonal replacement therapy, and prior use of oral contraceptive pills. Statistical analyses were performed with Microsoft Excel, SPSS Version 25 and WinPepi software.

\section{Results}

Clinical Characteristics 
The study group consisted of 330 patients. They included 198 BRCA1 mutation carriers and 108 BRCA2 mutation carriers; 2 women had a mutation in both BRCA1 and BRCA2. Of the remainder, one woman carried a mutation in PTEN, 16 had a family history of breast cancer but no recognized mutation, and 5 had a family history of $B R C A$ mutation but had opted not to have a genetic test themselves. The median duration of follow-up was 5.4 years (range, $0.03-18.2$ ), and the median age at the beginning of follow-up at the clinic was 37.4 years (range, 18.3-73.7). The clinical characteristics of the study group are presented in Table 1. 
Table 1

Clinical Characteristics of the Study Sample

\begin{tabular}{|l|l|}
\hline Characteristics & Count \\
\hline Mutation & \\
\hline BRCA1 & 198 \\
\hline 185delAG & 142 \\
\hline 5382insC & 33 \\
\hline Tyr978X & 6 \\
\hline Other & 10 \\
\hline Unknown & 7 \\
\hline BRCA2 & 108 \\
\hline 6174delT & 101 \\
\hline Other & 6 \\
\hline Unknown & 1 \\
\hline BRCA1 + BRCA2 & 2 \\
\hline PTEN & 1 \\
\hline Not a carrier & 16 \\
\hline No BRCA test & 5 \\
\hline History of malignancy & 296 \\
\hline None & 7 \\
\hline Ovarian cancer & 9 \\
\hline SCC, BCC & Basal carcinoma \\
\hline Melanoma & \\
\hline Other & 3 \\
\hline SCC = Squamous cell carcinoma: BCC & \\
\hline
\end{tabular}

Biopsy Analysis, Study Group

A total of 142 lesions were identified in the study group by various modalities: 76 (53.5\%) by MRI, 31 (21.8\%) by physical examination, 17 (12\%) by ultrasound and 11 (7.7\%) by mammography (Table 2$)$. Of the 31 lesions discovered by physical examination, 13 were found on the first or second visit at the clinic, 
before MRI was performed; 6 were breast skin lesions; 2 were found on self-examination; and 10 (32.2\%) were identified a short time after a negative MRI.

Table 2

Modalities Leading to a Biopsy

\begin{tabular}{|c|c|c|c|c|c|c|}
\hline \multirow[t]{2}{*}{ Modality } & \multicolumn{2}{|c|}{ Malignant } & \multicolumn{2}{|c|}{ Benign } & \multicolumn{2}{|c|}{ Total } \\
\hline & $\mathbf{N}$ & $\%$ & $\mathbf{N}$ & $\%$ & $\mathbf{N}$ & $\%$ \\
\hline Physical examination & 7 & 18.9 & 24 & 22.9 & 31 & 21.8 \\
\hline US & 4 & 10.8 & 13 & 12.4 & 17 & 12 \\
\hline MRI & 19 & 51.4 & 57 & 54.3 & 76 & 53.5 \\
\hline Mammography & 6 & 16.2 & 5 & 4.8 & 11 & 7.7 \\
\hline Unknown & 1 & 2.7 & 6 & 5.7 & 7 & 4.9 \\
\hline
\end{tabular}

All 142 lesions were biopsied: 117 Tru-cut breast biopsies, 13 fine-needle aspirations, 8 breast skin biopsies, and 4 diagnostic lumpectomies. The median patient age at biopsy was 41.5 years. The biopsy characteristics and pathology results are presented in Table 3. A malignancy was identified in 37 samples (26.1\%), including 7 prompted by physical examination. The total biopsy rate per 1000 follow-up-years was 69.8 . The positive biopsy rate per 1000 follow-up-years was 18.2 , and the positive biopsy percentage [(number of positive biopsies / number of total biopsies) $\times 100$ ] was $26.1 \%$. 
Table 3

Biopsy Characteristics

$\mathrm{N}$ (\% of biopsies)

Type of biopsy $(\mathrm{N}=142)$

Tru-cut breast biopsy

Fine needle aspiration

Breast skin biopsy

Excisional biopsy

Type of malignancy $(\mathrm{N}=37)$

IDC $26(70.27)$

DCIS

IDC + DCIS

ILC

Desmoid

$1(2.7)$

Type of benign lesions $(N=105)$

Fibroadenoma

$11(10.48)$

Proliferative changes

41 (39.05)

Benign breast tissue

38 (36.19)

Others

15 (14.29)

IDC = Invasive ductal carcinoma; DCIS = Ductal carcinoma in situ; ILC = Invasive lobular carcinoma

Comparison with the General Population

Findings for the $61 B R C A$ mutation carriers aged 50 years or more and 610 women of the same age who underwent routine breast cancer screening are presented in Tables 4 and 5, and the correction of confounding factors is shown in Table 6. IRR's (incidence rate ratio) and significance were calculated using Mid-P values. All IRR's- for negative, positive and total number of biopsies were found significant. The total biopsy rate per 1000 follow-up-years was 61.7 in the study group and 22.7 in the control group $(p<0.001)$. The positive biopsy rate per 1000 follow-up-years was 26.4 in the study group and 2.0 in the control group $(p<0.001)$. The positive biopsy percentages [(number of positive biopsies / number of total biopsies $) \times 100]$ were $42.9 \%$ in the study group and $8.7 \%$ in the control group $(p<0.0001)$. 
Table 4

Results of Biopsies in the BRCA and the General Population Cohorts

\begin{tabular}{|lllll|}
\hline & \multicolumn{2}{l}{ BRCA mutation carriers } & \multicolumn{2}{l|}{ Control group } \\
& N & N of Patients & N & N of Patients \\
\hline Total biopsies & 21.0 & 61 & 138.0 & 610 \\
\hline Positive biopsies & 9.0 & 61 & 12.0 & 610 \\
\hline Negative biopsies & 12.0 & 61 & 126.0 & 610 \\
\hline Years of Follow-up & 340.6 & 61 & 6088.2 & 610 \\
\hline
\end{tabular}

Table 5

Biopsy Rate for 1000 Years of Follow-Up

\begin{tabular}{|lllll|}
\hline & BRCA mutation carriers & Control group & Ratio & P-Value \\
\hline Total biopsies & 61.7 & 22.7 & 2.7 & $\mathrm{p}<0.001$ \\
\hline Positive biopsies & 26.4 & 2.0 & 13.4 & $\mathrm{p}<0.001$ \\
\hline Negative biopsies & 35.2 & 20.7 & 1.7 & $\mathrm{p}=0.048$ \\
\hline
\end{tabular}


Table 6

Parameters which were included in matched analysis

\begin{tabular}{|c|c|c|c|c|c|}
\hline & & \multicolumn{2}{|c|}{ BRCA mutation carriers } & \multicolumn{2}{|c|}{ Control group } \\
\hline & & $\mathrm{N}$ & $\%$ & $\mathrm{~N}$ & $\%$ \\
\hline \multirow[t]{4}{*}{ Age group } & 50 & 37 & 60.7 & 370 & 60.7 \\
\hline & $51-55$ & 14 & 23.0 & 140 & 23.0 \\
\hline & $56-60$ & 8 & 13.1 & 80 & 13.1 \\
\hline & $61-65$ & 2 & 3.3 & 20 & $3.3 \%$ \\
\hline \multirow[t]{3}{*}{ Charlson score } & 0 & 39 & 63.9 & 390 & 63.9 \\
\hline & 1 & 13 & 21.3 & 130 & 21.3 \\
\hline & $2-3$ & 9 & 14.8 & 90 & 14.8 \\
\hline \multirow[t]{2}{*}{ Sector } & Orthodox Jewish & 2 & 3.3 & 20 & $3.3 \%$ \\
\hline & non-orthodox Jewish & 59 & 96.7 & 590 & 96.7 \\
\hline \multirow[t]{2}{*}{ Hormone replacement therapy } & 0 & 44 & $72.1 \%$ & 440 & 72.1 \\
\hline & 1 & 17 & $27.9 \%$ & 170 & 27.9 \\
\hline \multirow[t]{2}{*}{ Oral contraceptives } & 0 & 55 & $90.2 \%$ & 550 & 90.2 \\
\hline & 1 & 6 & $9.8 \%$ & 60 & $9.8 \%$ \\
\hline
\end{tabular}

\section{Discussion}

BRCA mutation carriers undergo intensive breast follow-up, including breast-imaging scans such as mammography and MRI. Since the tests often identify suspicious findings, these women are frequently referred for biopsy studies. The present study evaluated the total biopsy rate, the positive biopsy rate, and the positive biopsy percentage among BRCA mutation carriers compared to the general population of women referred for routine screening. We sought to investigate the load of biopsy rate requested from $B R C A$ mutation carriers who participate in a dedicated clinic.

Our matched analysis revealed that $B R C A$ mutation carriers have a 2.7 times higher biopsy rate per 1000 follow-up-years, a 13.2 times higher positive biopsy rate per 1000 follow-up-years, and a 4.9 times higher positive biopsy percentage compared with the general population of women undergoing routine breast cancer screening. Of note, despite of higher percentage of positive biopsies in the group of BRCA mutation carriers, still most of the biopsies performed by BRCA carriers who have attended the clinic (73.9\%) revealed benign lesions. This is in accordance with a study of healthy $B R C A$ mutation carriers followed at another high-risk clinic in Israel that also found that the vast majority of biopsies performed (72\%) were benign [13]. Another study examined biopsies of women with dense breast tissue who 
undergo breast MRI as part of their follow-up. Although results cannot be compared across studies due to the different screening structure, both studies are comprised of high-risk women who require MRI as part of their screening program. The percentage of malignant results were comparable between the studies: $26.1 \%$ in our study compared to $31 \%$ in the dense breast study [14]. Both studies reflect the need for personalized screening regimens [15]. Of note, we could not find a published matched analysis as was presented here.

An unexpected incidental finding of this study was the role of physical examination, which was the second most important modality after MRI in the identification of suspicious lesions during follow-up. Of note, in one-third of cases, the requested MRI test was not performed on time. These mainly happened in patients who were new to the clinic.

This study has several limitations. The retrospective methodology may cause a bias due to unknown or unrecorded confounders. The main limitation of this study was our inability to perform a matched analysis for the under-50 age group because routine screening mammography is recommended only for women age 50 or older whereas BRCA mutation carriers start much earlier. Second, a different screening protocol was used in the two groups. The high-risk protocol includes more frequent imaging, including MRI, which is known to be associated with a relatively high prevalence of false-positive results [16]. Moreover, most of the carriers have started screening at an earlier age. It is known that the false positive in the first year of screening is higher than in later years, this may suggest that the difference between the groups is even bigger than was seen in this study [17].

It should be emphasized that the study meant to mirror a given situation derived from adherence to the national and international guidelines, and in that perspective, it is clearly describes the differences in load of biopsies and their outcomes between these 2 populations.

Clinical Implications: To our knowledge, this is the first study to evaluate the total biopsy and the positive biopsy rates among $B R C A$ mutation carriers in comparison to the general population. Our data is important both to the patient and to the care givers to better understand the "pathway of the carrier" when joining a dedicated clinic. This information is also helpful for health authorities when regulating resources and costs. Moreover, repeated imaging and biopsies are stressful, and for some women, have a considerable negative impact on quality of life. Providing these patients with detailed information on the process and outcomes of follow-up can contribute to their feeling of health safety, and can be a major psychological predictor when considering a prophylactic surgery $[18,19]$.

The information provided by the present study takes on additional importance in light of the increasing awareness of the importance of BRCA testing in the high-risk population and the suggestion that the test should be offered as a screening test for women of Ashkenazi Jew ancestry [20]. Given the fact that about $2.5 \%$ of the Ashkenazi Jews carry a $B R C A$ mutation [7], we are expecting to see a lot more $B R C A$ carriers. 
The high positive biopsy percentage in our study group is in line with current international recommendations for follow-up of $B R C A$ carriers and should be part of the quality assurance considerations of the team that assesses the requirements for performing biopsy tests.

The study may support earlier reports suggesting that dedicated $B R C A$ clinics effectively meet the specific short- and long-term needs of this high-risk population [11].

\section{Declarations}

Funding None.

Conflicts of interest/Competing interests Conflicts of interest are reported, all outside the submitted work.

Availability of data and material The datasets generated during and/or analyzed during the current study are not publicly available but are available from the corresponding author on reasonable request.

Code availability NA

Ethics approval The study was approved by the local Institutional Ethics Committee.

Consent to participate Was not required by the Ethic Committee.

Consent for publication Is given by all the authors.

\section{References}

1. Jemal A, Bray F, Center MM, Ferlay J, Ward E, Forman D (2011) Global cancer statistics. CA Cancer J Clin 61:69-90. https://doi.org/10.3322/caac.20107

2. Stuckey A (2011) Breast cancer: epidemiology and risk factors. Clin Obstet Gynecol 54(1);96-102. https://doi.org/10.1097/GRF.0b013e3182080056

3. Hall JM, Lee MK, Newman B, Morrow JE, Anderson LA, Huey B, King MC (1990) Linkage of early-onset familial breast cancer to chromosome 17q21. Science 250:1684-9.

https://doi.org/10.1126/science.2270482

4. Miki Y, Swensen J, Shattuck-Eidens D, Futreal PA, Harshman K, Tavtigian S, Liu Q, Cochran C, Bennett LM, Ding W, Bell R, Rosenthal J, Hussey C, Tran T, McClure M, Frye C, Hattier T, Phelps R, Haugen-Strano A, Katcher H, Yakumo K, Gholami Z, Shaffer D, Stone S, Bayer S, Wray C, Bogden R, Dayananth P, Ward J, Tonin P, Narod S, Bristow PK, Norris FH, Helvering L, Morrison P, Rosteck P, Lai M, Barrett JC, Lewis C, Neuhausen S, Cannon-Albright L, Goldgar D, Wiseman R, Kamb A, Skolnick MH (1994) A strong candidate for the breast and ovarian cancer susceptibility gene BRCA1. Science 266:6671. https://doi.org/10.1126/science.7545954 
5. Wooster R, Bignell G, Lancaster J, Swift S, Seal S, Mangion J, Collins N, Gregory S, Gumbs C, Micklem G (1995) Identification of the breast cancer susceptibility gene BRCA2. Nature 378:789-

92. https://doi.org/10.1038/378789a0

6. Whittemore AS, Gong G, John EM, McGuire V, Li FP, Ostrow KL, Dicioccio R, Felberg A, West DW (2004) Prevalence of BRCA1 mutation carriers among U.S. non-Hispanic Whites. Cancer Epidemiol Biomarkers Prev 13:2078-83.

7. Roa BB, Boyd AA, Volcik K, Richards CS (1996) Ashkenazi Jewish population frequencies for common mutations in BRCA1 and BRCA2. Nature Genet 14:185-7. https://doi.org/10.1038/ng1096-185

8. USPSTF (2016) Breast Cancer: Screening. U.S Preventive Services Task Force. https://www.uspreventiveservicestaskforce.org/Page/Document/UpdateSummaryFinal/breastcancer-screening. Accessed 9 March 2021

9. ASBrS (2019) Position Statement on Screening Mammography. The American Society of Breast Surgeons.

https://www.breastsurgeons.org/docs/statements/Position-Statement-on-Screening-Mammography.pdf Accessed 9 March 2021

10. Daly MB, Pal T, Berry MP, Buys SS, Dickson P, Domchek SM, Elkhanany A, Friedman S, Goggins M, Hutton ML; CGC, Karlan BY, Khan S, Klein C, KohImann W; CGC, Kurian AW, Laronga C, Litton JK, Mak JS; LCGC, Menendez CS, Merajver SD, Norquist BS, Offit K, Pederson HJ, Reiser G; CGC, Senter-Jamieson L; CGC, Shannon KM, Shatsky R, Visvanathan K, Weitzel JN, Wick MJ, Wisinski KB, Yurgelun MB, Darlow SD, Dwyer MA (2021) Genetic/Familial High-Risk Assessment: Breast, Ovarian, and Pancreatic, Version 2.2021, NCCN Clinical Practice Guidelines in Oncology. J Natl Compr Canc Netw 19(1):77-

102. https://doi.org/10.6004/jnccn.2021.0001

11. Yerushalmi R, Rizel S, Zoref D, Sharon E, Eitan R, Sabah G, Grubstein A, Rafson Y, Cohen M, Magen A, Birenboim I, Margel D, Ozlavo R, Sulkes A, Brenner B, Perry S (2016) A dedicated follow-up clinic for BRCA mutation carriers. Isr Med Assoc J 18(9):549-552.

12. D’Orsi CJ, Sickles EA, Mendelson EB, Morris EA, et al. (2013) ACR BI-RADS® Atlas, Breast Imaging Reporting and Data System. Reston, VA

13. Laitman Y, Madorsky Feldman D, Sklair-Levy M, Yosepovich A, Barshack-Nakar I, Brodsky M, Halshtok O, Shalmon A, Gotlieb M, Friedman E (2018) Abnormal findings detected by multi-modality breast imaging and biopsy results in a high-risk clinic. Clin Breast Cancer 18(4):695-698. https://doi.org/10.1016/j.clbc.2017.12.005

14. Weinstein SP, Korhonen K, Cirelli C, Schnall MD, McDonald ES, Pantel AR, Zuckerman S, Borthakur A, Conant EF (2020) Abbreviated Breast Magnetic Resonance Imaging for Supplemental Screening of 
Women With Dense Breasts and Average Risk. J Clin Oncol 38(33):3874-3882.

https://doi.org/10.1200/JC0.19.02198

15. Allweis TM, Hermann N, Berenstein-Molho R, Guindy M (2021) Personalized Screening for Breast Cancer: Rationale, Present Practices, and Future Directions. Ann Surg Oncol.

https://doi.org/10.1245/s10434-020-09426-1

16. Houssami N, Hayes DF (2009) Review of preoperative magnetic resonance imaging (MRI) in breast cancer: should MRI be performed on all women with newly diagnosed, early stage breast cancer? CA Cancer J Clin 59(5):290-302. https://doi.org/10.3322/caac.20028

17. D’Orsi CJ (2020) The Clinically Relevant Breast Imaging Audit. J Breast Imaging 2(1):2-6. https://doi.org/10.1093/jbi/wbz080

18. Butler E, Collier S, Hevey D (2020) The factors associated with distress a minimum of six months after BRCA1/2 confirmation: A systematic review. J Psychosoc Oncol 22:1-

27. https://doi.org/10.1080/07347332.2020.1836109

19. Segerer R, Peschel C, Kämmerer U, Häussler S, Wöckel A, Segerer S (2020) Factors Impacting on Decision-Making towards Prophylactic Surgeries in BRCA Mutation Carriers and Women with Familial Predisposition. Breast Care (Basel) 15(3):253-259. https://doi.org/10.1159/000503370

20. Lieberman S, Tomer A, Ben-Chetrit A, Olsha O, Strano S, Beeri R, Koka S, Fridman H, Djemal K, Glick I, Zalut T, Segev S, Sklair M, Kaufman B, Lahad A, Raz A, Levy-Lahad E (2017) Population screening for BRCA1/BRCA2 founder mutations in Ashkenazi Jews: proactive recruitment compared with self-referral. Genet Med 19(7):754-762 https://doi.org/10.1038/gim.2016.182 